\title{
Reversible Thermodynamic Cycle for AMTEC Power Conversion
}

\author{
C.B. Vining, R.M. Williams, M.L. Underwood, M.A. Ryan, and J.W. Suitor \\ Jet Propulsion Laboratory/California Institute of Technology \\ Pasadena, California 91109 \\ AIO1-86CE 90237
}

\section{ABSTRACT}

The thermodynamic cycle appropriate to an AMTEC (alkali metal thermal-to-electric converter) cell is discussed for both liquid- and vapor-fed modes of operation, under the assumption that all processes can be performed reversibly. In the liquid-fed mode, the reversible efficiency is greater than $89.6 \%$ of Carnot efficiency for heat input and rejection temperatures (900-1300 K and 400-800 K, respectively) typical of practical devices. Vapor-fed cells can approach the efficiency of liquid-fed cells. Quantitative estimates confirm that the efficiency is insensitive to either the work required to pressurize the sodium liquid or the details of the state changes associated with cooling the low pressure sodium gas to the heat rejection temperature.

\section{INTRODUCTION}

An AMTEC cell is a static device for the conversion of heat to electricity with the potential for reliable, long life operation and high conversion efficiency. The general principles governing operation of an AMTEC cell have been described in detail elsewhere, ${ }^{1,2,3}$ so only a brief outline will be provided here.

The key component of an AMTEC cell is the $\beta^{\prime \prime}$ alumina solid electrolyte (BASE), which conducts positive sodium ions much more readily than sodium atoms or electrons. A sodium pressure difference across a thin BASE sheet will drive sodium ions from the high pressure side to the low pressure side. Positive sodium ions accumulate on the low pressure side and electrons collect on the high pressure side, resulting in an electrical potential which balances the pressure differential and prevents further flow of sodium ions.

With appropriate electrodes, this electrical potential can be utilized to drive an electrical current through a load. The unusual properties of the BASE, therefore, provide a method of converting mechanical energy, represented by the pressure differential, into electrical energy. Or, using a more conventional description of the same process, the BASE converts a chemical potential difference into an electrical potential difference. The efficiency of this final conversion to electrical energy is governed by a variety a of irreversible kinetic and transport processes occurring at the electrode interfaces and within the BASE material itself., 4

The thermal-to-electric conversion process is completed by condensing the low pressure gas, pressurizing the resulting liquid and returning the sodium to the high pressure side of the BASE. Irreversible kinetic and transport losses are also experienced in these processes and a number of efforts are underway to develop practical, high efficiency cells. 6,7

An AMTEC cell, therefore, may be described as performing two distinct energy conversion processes: 1) conversion of heat to mechanical energy via a sodium-based heat engine and 2) conversion of mechanical energy to electrical energy by utilizing the special properties of the BASE material. While the essential thermodynamic aspects of the sodium-based heat engine have been previously described $^{2}$, no detailed discussion of the relevant thermodynamic cycle has yet been presented.

This paper provides a description of the thermodynamic cycle appropriate for an AMTEC cell, neglecting all irreversible processes. In particular, losses related to internal impedances, thermal conduction, and all processes within the BASE/electrode(s) are entirely neglected. The thermodynamic properties of sodium liquid and vapor are taken into account using parameterizations of experimental results as summarized by Bomelburg et $\mathrm{al}^{8}$.

\section{LIQUID-FED AMTEC CYCLE}

Figure 1 shows a schematic for a simple, liquid-fed AMTEC cell. Figures 2 and 3 show the appropriate pressurevolume (p-v) and temperature-entropy (T-s) diagrams for operation between $1100 \mathrm{~K}$ and $1200 \mathrm{~K}$. The dotted lines in each figure indicate the properties of saturated sodium liquid and gas. The points (a) through (g) indicate the same thermodynamic state for sodium in each of these three figures. The small temperature difference of $100 \mathrm{~K}$ was chosen merely to illustrate certain qualitative features to be discussed below. A more practical AMTEC device would operate with a heat rejection temperature in the range of 400 $\mathrm{K}$ to $800 \mathrm{~K}$ and a heat input temperature in the range of 900 $\mathrm{K}$ to $1300 \mathrm{~K}$. 


\section{DISCLAIMER}

This report was prepared as an account of work sponsored by an agency of the United States Government. Neither the United States Government nor any agency Thereof, nor any of their employees, makes any warranty, express or implied, or assumes any legal liability or responsibility for the accuracy, completeness, or usefulness of any information, apparatus, product, or process disclosed, or represents that its use would not infringe privately owned rights. Reference herein to any specific commercial product, process, or service by trade name, trademark, manufacturer, or otherwise does not necessarily constitute or imply its endorsement, recommendation, or favoring by the United States Government or any agency thereof. The views and opinions of authors expressed herein do not necessarily state or reflect those of the United States Government or any agency thereof. 


\section{DISCLAIMER}

Portions of this document may be illegible in electronic image products. Images are produced from the best available original document. 


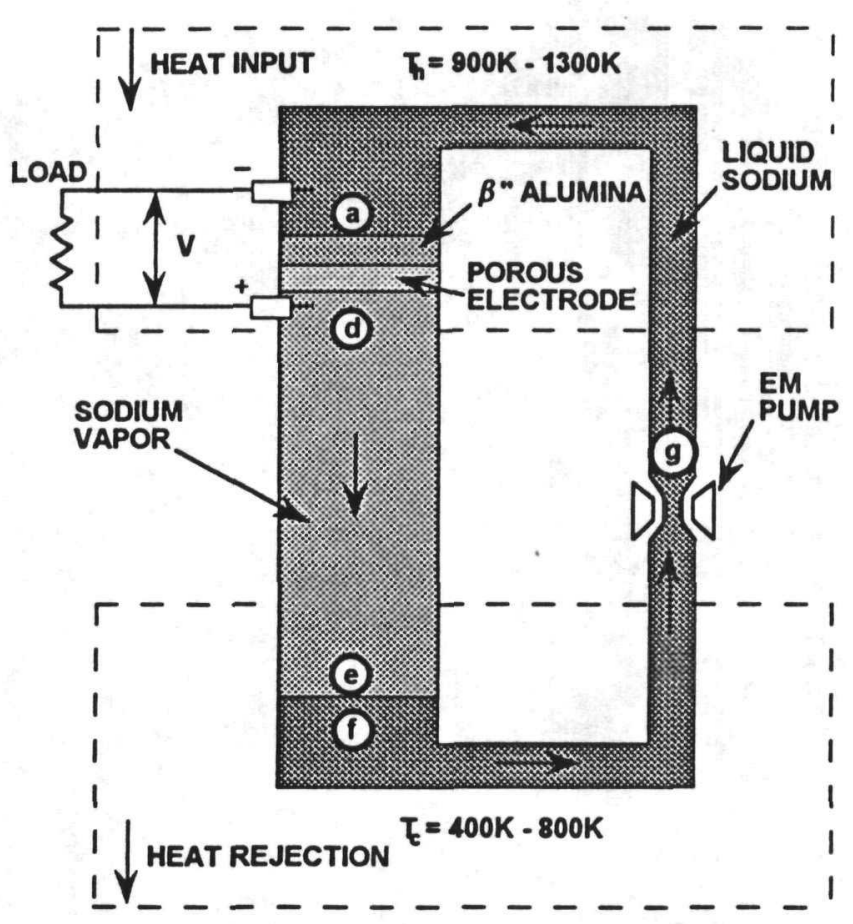

Figure 1. Schematic of a liquid-fed AMTEC cell

Compressed sodium liquid is delivered to the BASE/electrode at $1200 \mathrm{~K}$, as indicated by the point (a). Sodium gas emerges from the BASE/electrode, also at $1200 \mathrm{~K}$ but at a much reduced pressure as indicated by the point (d). Between the points (a) and (d) the BASE/electrode ionizes the sodium atoms, provides power to the electrical load, and recombines the sodium ions with electrons to form sodium gas.

The $p-v$ state path (a-b-c-d) shown in Figure 2 represents the following isothermal processes:

(a-b) de-pressurization of the liquid;

(b-c) vaporization of the saturated liquid; and

(c-d) expansion the resulting gas to a low pressure.

This $\mathrm{p}-\mathrm{v}$ path is very different from the physical processes

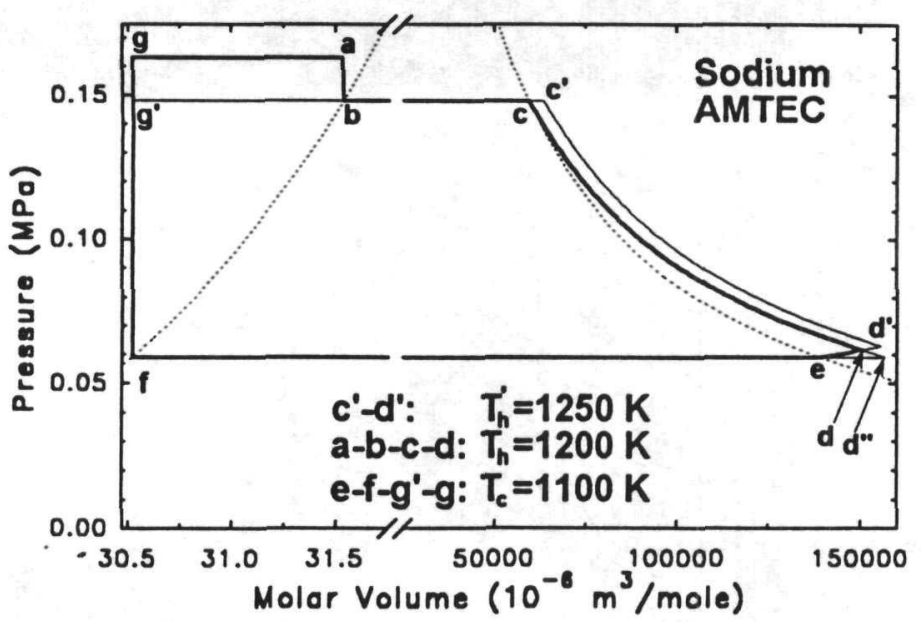

Figure 2. Pressure-volume diagram for a reversible sodium AMTEC cycle operating between $1100 \mathrm{~K}$ and $1200 \mathrm{~K}$. Note the false zero and break in scale on the volume axis. occurring within BASE/electrode, but the p-v process is thermodynamically equivalent in the sense that the same amount of reversible work is performed. The T-s diagram in Figure 3 is perhaps more clear in this respect since any isothermal process connecting sodium liquid at (a) to sodium gas at (d) must be a horizontal line, regardless of the details of the processes.

The work associated with the de-pressurization process (a-b) can be estimated as follows. The isothermal bulk modulus of liquid sodium varies from about 5 to $2 \mathrm{GPa}$ between $400 \mathrm{~K}$ and $1300 \mathrm{~K}^{8}$ The maximum pressure change of interest in an AMTEC cell is at most on the order of the saturation vapor pressure (about $0.3 \mathrm{MPa}$ or 3 atmospheres at $1300 \mathrm{~K}$ ). The fractional volume change can therefore be estimated as on the order of $2 \times 10^{-4}$ (about $0.02 \%$ ) which is why the line (a-b) in Figure 2 appears to be completely vertical. The fractional entropy change is similarly estimated as about $10^{-8}$, which is why the points $(a, b)$ cannot be distinguished from each other in Figure 3. These estimates confirm that liquid sodium may be treated as incompressible at the temperatures and pressures under consideration.

Upon leaving the BASE/electrode at (d), the sodium cools to the condenser temperature indicated at (e). It is commonly assumed that the gas is sufficiently diffuse in this region that the mean free path of a sodium atom is greater then the cell dimensions. ${ }^{2}$ This is variously described as the 'Langmuir assumption' or a 'Knudsen flow regime.' Under these conditions $p / \sqrt{T}=a$ constant and such a diffuse gas can support a pressure differential. Although a long mean free path is implied by the process (d-e) indicated in Figures 2 and 3, this is for illustrative purposes only since the mean free path is not actually long at such high condenser temperatures, as will be discussed below.

Along (d-f) the gas condenses isothermally and a pump (f-g) increases the pressure in order to maintain the liquid

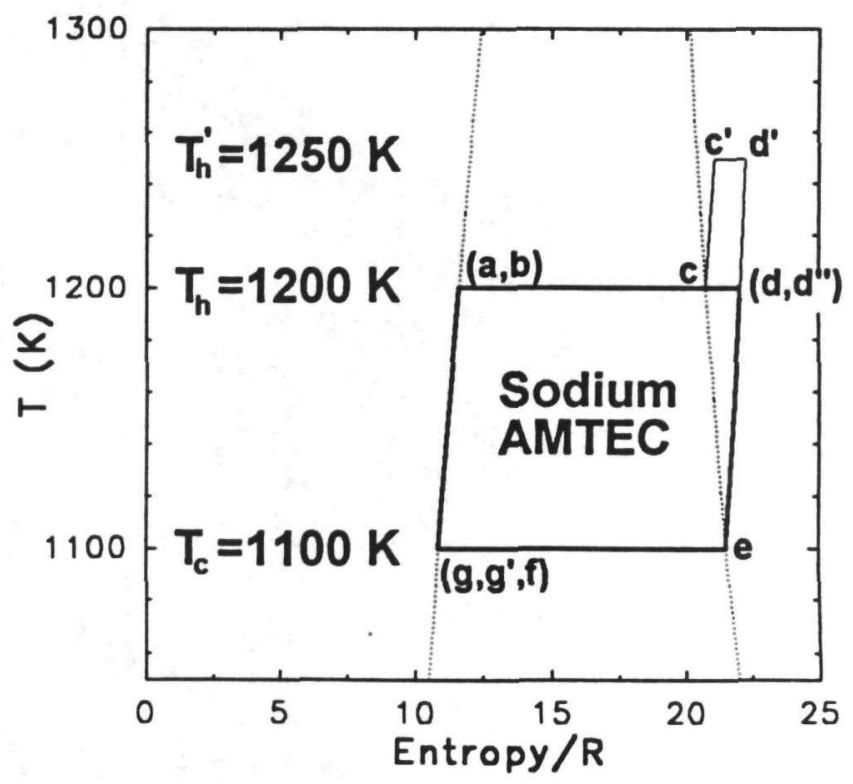

Figure 3. Temperature-entropy diagram for a reversible sodium AMTEC cycle operating between $1100 \mathrm{~K}$ and $1200 \mathrm{~K}$. 
state as the sodium is heated along ( $g-a)$ to the temperature of the BASE/electrode $(1200 \mathrm{~K}$, in this example). The pump must produce a pressure at least as large as the saturation pressure at the BASE/electrode temperature. This minimum pressure is indicated by the point $\left(\mathrm{g}^{\prime}\right)$ in Figure 2 .

Since the liquid is so nearly incompressible, there is no significant loss in over-pressurizing the liquid to the point (g), providing a margin of safety to assure a liquid-fed mode of operation. For example, if the pump is adiabatic along the step ( $\mathrm{f}-\mathrm{g}$ ), the temperature of the liquid increases by only about $4 \times 10^{-6} \mathrm{~K}$ and the volume decreases by only 30 parts per million.

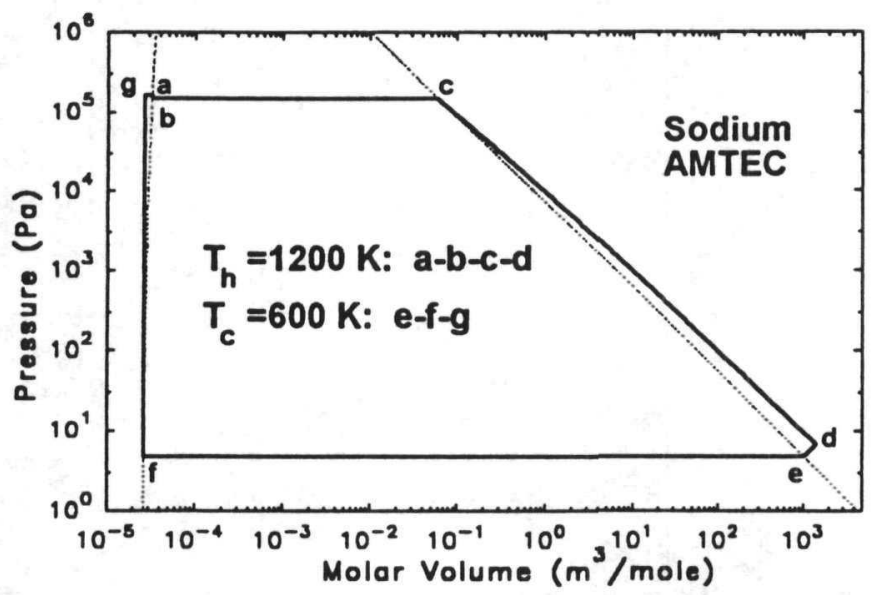

Figure 4. Pressure-volume diagram for a reversible sodium AMTEC cycle operating between $600 \mathrm{~K}$ and $1200 \mathrm{~K}$.

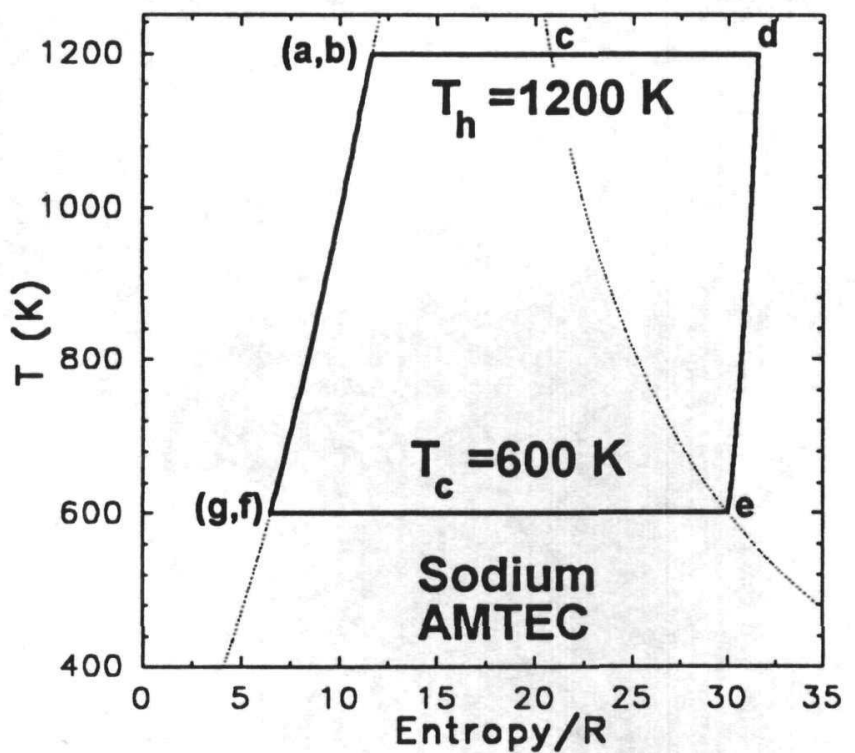

Figure 5. Temperature-Entropy diagram for a reversible sodium AMTEC cycle operating between $600 \mathrm{~K}$ and $1200 \mathrm{~K}$.

Figures 4 and 5 show $p-v$ and T-s diagrams for a reversible, liquid-fed AMTEC cell operating between $600 \mathrm{~K}$ and $1200 \mathrm{~K}$, typical of the temperatures anticipated for space applications. Here again, the dotted lines indicate the properties of saturated sodium liquid and gas. The large variation of the pressure and molar volume in this case require plotting the p-v diagram using logarithmic scales, so the areas under the curves no longer directly correspond work.

The efficiency of the AMTEC cycle may be calculated from the T-s diagrams such as Figures 3 and 5 in the usual way:

$$
\eta=\frac{\text { Net Work }}{\text { Heat In }}=\frac{\text { Area within }(a-b-c-d-e-f-g-a)}{\text { Area under }(g-a-b-c-d)} .
$$

Figure 6 shows the efficiency for a reversible, liquid-fed AMTEC cell as a function of the heat input temperature $\left(T_{h}\right)$ and the heat rejection temperature $\left(T_{c}\right)$. Over the entire temperature range of interest, the efficiency is greater than $89.6 \%$ of the ideal Carnot efficiency $\left(1-\mathrm{T}_{d} / \mathrm{T}_{\mathrm{h}}\right)$. Weber ${ }^{2}$ has estimated the efficiency of an AMTEC device with $T_{h}=1000$ $\mathrm{K}$ and $\mathrm{T}_{\mathrm{c}}=500 \mathrm{~K}$ as $48.6 \%$, or $97.2 \%$ of Carnot. Under these conditions we find from Figure 6 an efficiency of $93.4 \%$, which is slightly lower than Weber's result but still quite efficient.

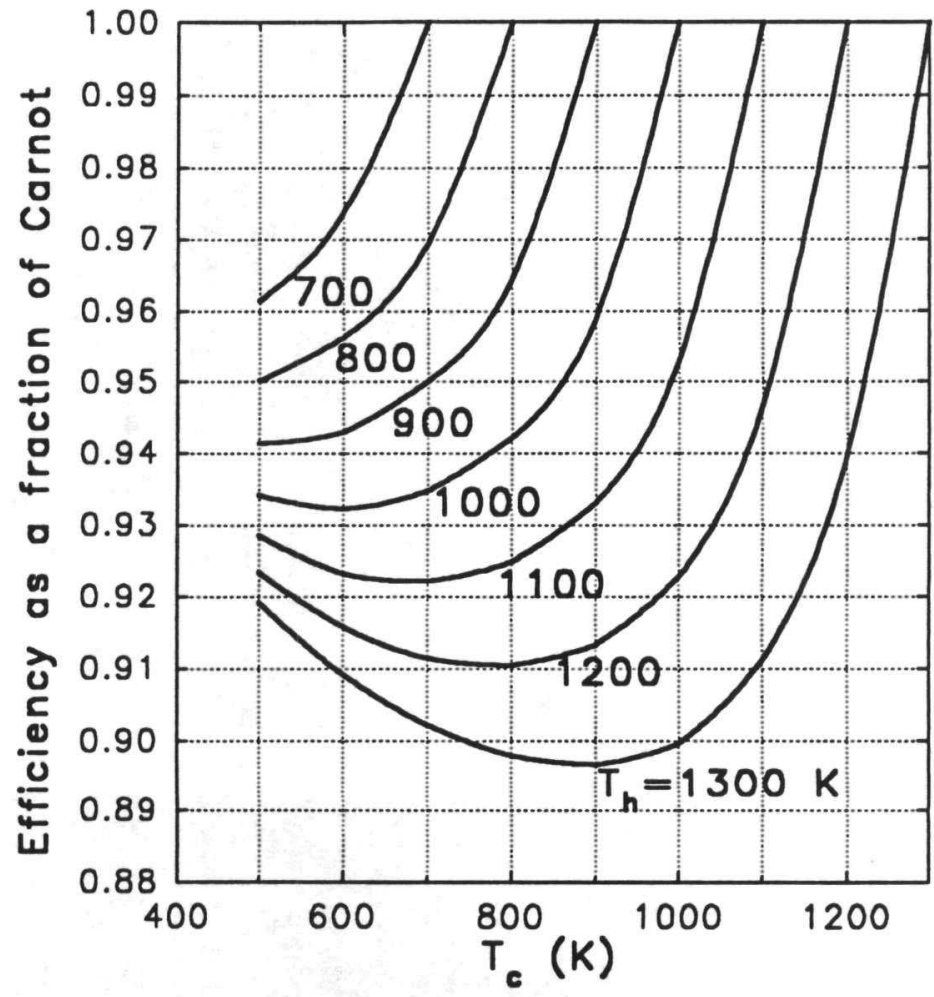

Figure 6. Efficiency as a fraction of the ideal Carnot efficiency for a reversible, liquid-fed sodium AMTEC cycle.

\section{VAPOR-FED AMTEC CYCLE - with condensate}

There are two types of AMTEC cells which involve vaporization of sodium during heat input. In the first type of cell, liquid sodium is heated to a temperature greater than the temperature of the BASE and vaporized. Then, the sodium gas is transported to the BASE where it condenses. No work is performed by this vaporization and condensation cycle and ideally all the heat input is delivered to the BASE. From this point on, the conversion process continues just as described above for the liquid-fed AMTEC cell. The efficiency of this 
type of cell will be identical to the analagous liquid cell efficiencies shown in Figure 6, where now $T_{h}$ and $T_{c}$ refer to the BASE temperature and the heat rejection temperature, respectively. Cells of this type have actually been constructed and offer potential advantages particularly with regard to sodium transport in zero gravity. ${ }^{9}$

\section{VAPOR-FED AMTEC CYCLE - without condensate}

The second type of vapor-fed cycle involving vaporization of sodium during heat input is referred to as a vapor-vapor AMTEC cell ${ }^{10}$ In this case, shown schematically in Figure 7, sodium is vaporized in the boiler and remains in the vapor state as it is heated to the BASE/electrode temperature. Figures 2 and 3 show the appropriate $\mathrm{p}-\mathrm{v}$ and $\mathrm{T}-\mathrm{s}$ diagrams, respectively, for a vaporvapor cell as indicated by the curves ( $\left.c^{\prime}-d^{\prime}-e-f-g^{\prime}-b-c^{\prime}\right)$. In this example the BASE/electrode is at $1250 \mathrm{~K}$, sodium is vaporized at $1200 \mathrm{~K}$ and condensed at $1100 \mathrm{~K}$.

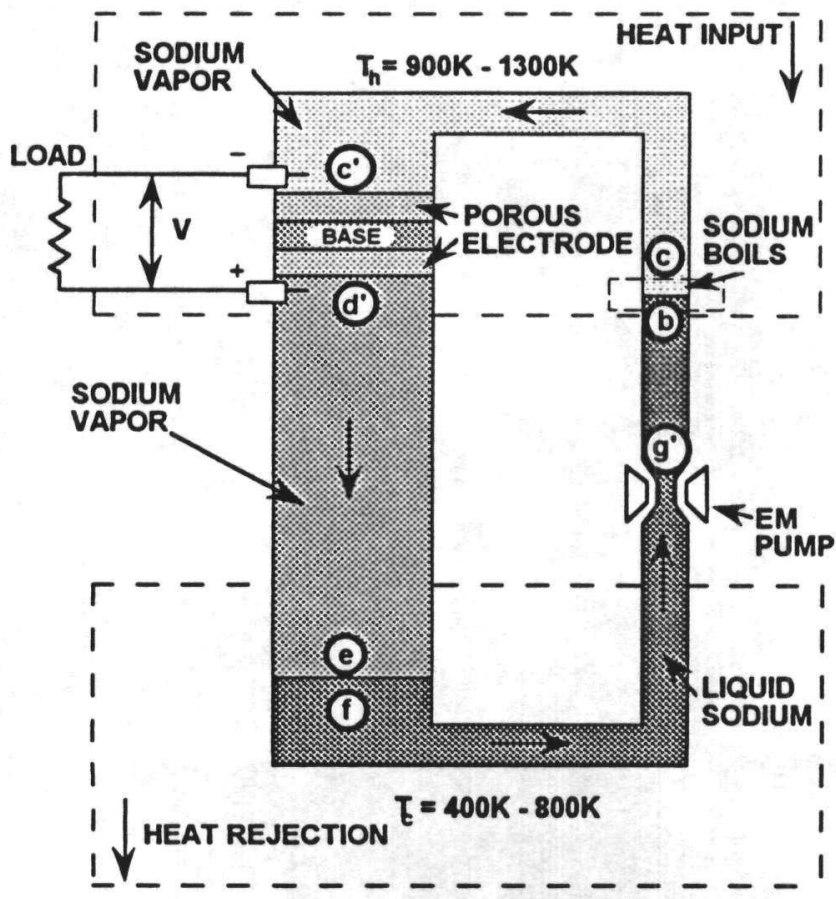

Figure 7. Schematic of a vapor-vapor AMTEC cell

High pressure sodium gas is delivered to the BASE/electrode at $\left(c^{\prime}\right)$, emerging isothermally with a much reduced pressure at $\left(d^{\prime}\right)$. The vapor cools along $\left(d^{\prime}-e\right)$ with $p / \sqrt{T}=a$ constant, again assuming the gas mean free path is longer than the cell dimensions. The cool sodium gas condenses along (e-f) and is pressurized by a pump along ( $\mathrm{f}$ $\left.g^{\prime}\right)$. As discussed above, the temperature and volume changes of the liquid along this pressurization step are truly negligible

Along the path $\left(g^{\prime}-b-c-c^{\prime}\right)$ the high pressure liquid is in immediate contact with the high pressure gas and the processes are considered to be isobaric. The pressurized liquid is heated to the boiling temperature of $1200 \mathrm{~K}$ along $\left(g^{\prime}-b\right)$ where it vaporizes $(b-c)$ and then heats further $\left(c-c^{\prime}\right)$ to $1250 \mathrm{~K}$, the temperature of the BASE/electrode.

The efficiency of a vapor-vapor AMTEC cell will depend on the temperature of the BASE/electrode, the boiler temperature and the condenser temperature. For a BASE/electrode temperature ( $\left.c^{\prime}-\mathrm{d}^{\prime}\right)$ of $1200 \mathrm{~K}$ and a condenser temperature (e-f) of $600 \mathrm{~K}$, Figure 8 shows the effect of the boiler temperature on the efficiency. If the sodium gas enters the BASE/electrode immediately after boiling and the boiler temperature is the same as the BASE temperature, then the vapor-vapor cell is exactly as efficient as the liquid-fed cell. Boiling the sodium at the condenser temperature, of course, results in no pressure differential across the BASE and no work can be performed at all.

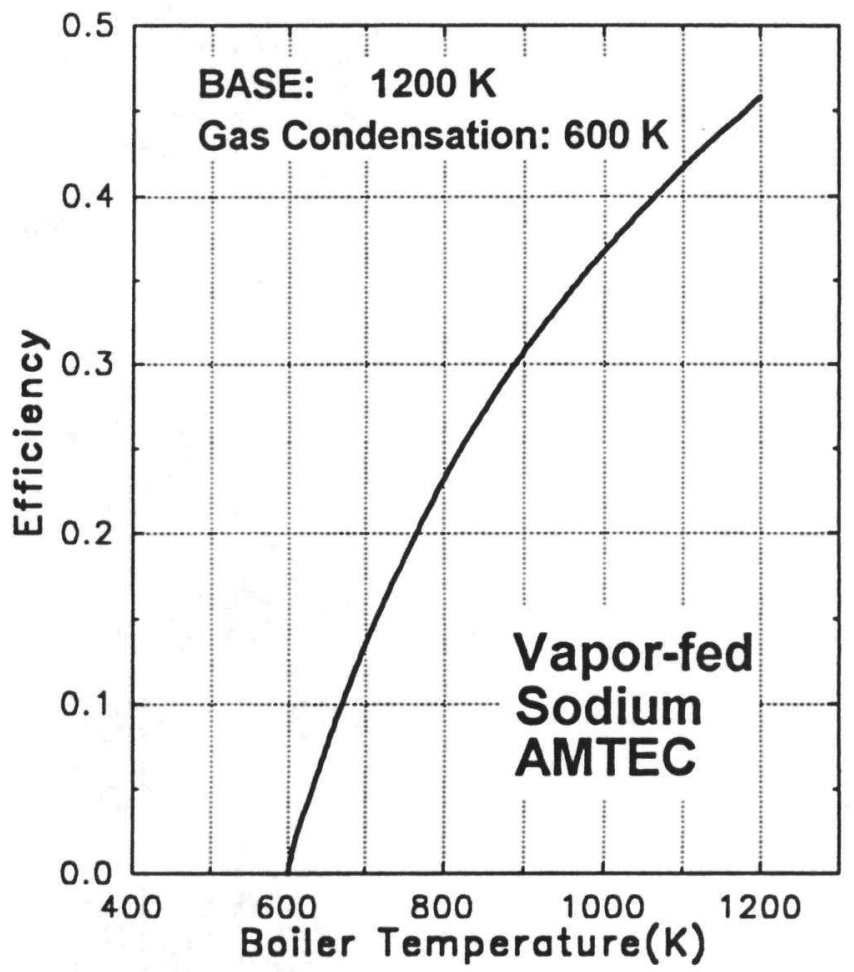

Figure 8. Effect of the boiler temperature on the efficiency of a reversible, vapor-vapor AMTEC cell operating between $600 \mathrm{~K}$ and $1200 \mathrm{~K}$.

A potential advantage is that the maximum pressure encountered in a vapor-vapor AMTEC cell is the saturation pressure at the boiler temperature, which can be much less than the saturation pressure at the BASE/electrode temperature. Decreasing the boiler temperature from $1200 \mathrm{~K}$ to $1000 \mathrm{~K}$, for example, decreases the efficiency from $45.8 \%$ to $36.8 \%$ while reducing the maximum pressure in the cell by almost a factor of 8 from $0.15 \mathrm{MPa}$ to $0.02 \mathrm{MPa}$. Another potential advantage is greater design flexibility since liquid sodium need not be delivered directly to the BASE/electrode. Of course, an additional porous electrode will also be required on the high pressure side of the BASE to provide electrical connections since the sodium gas is an electrical insulator.

\section{THE LONG MEAN FREE PATH ASSUMPTION}

Throughout the above analysis the long mean free path assumption has been adopted when considering low pressures sodium gas. In particular, this assumption has been applied to cooling of the sodium gas along segments labeled (d-e) or (d'-e). This section examines the impact of failing to satisfy the long mean free path assumption. 
A reasonable estimate of the mean free path may be obtained from

$$
I=\frac{\bar{V}}{N_{A} \pi d^{2}}
$$

where $\bar{V}$ is the molar volume, $N_{A}$ is Avogadro's number and $\mathrm{d}$ is the diameter of a sodium atom (taken as $3.8 \times 10^{-10} \mathrm{~m}$ ). The mean free path of saturated sodium gas is shown in Figure 9 as a function of temperature. Figure 9 indicates that the mean free path becomes comparable to typical cell dimensions (on the order of $0.01 \mathrm{~m}$ ) at temperatures above $570 \mathrm{~K}$. For condenser temperatures higher than $570 \mathrm{~K}$, the long mean free path assumption may not be well satisfied.

Figures 2 and 3 , for example, illustrate a condenser temperature of $1100 \mathrm{~K}$ where the sodium mean free path is less than $10^{-6} \mathrm{~m}$. Instead of the paths labeled (d-e) and (d'-e), the low pressure sodium gas should cool with virtually no pressure drop between the exit of the BASE/electrode and the condenser. In this case, the liquid-fed cell cycle is described by the path (a-b-c-d"-e-f-g-a), where the (d"-e) represents isobaric cooling of the sodium gas.

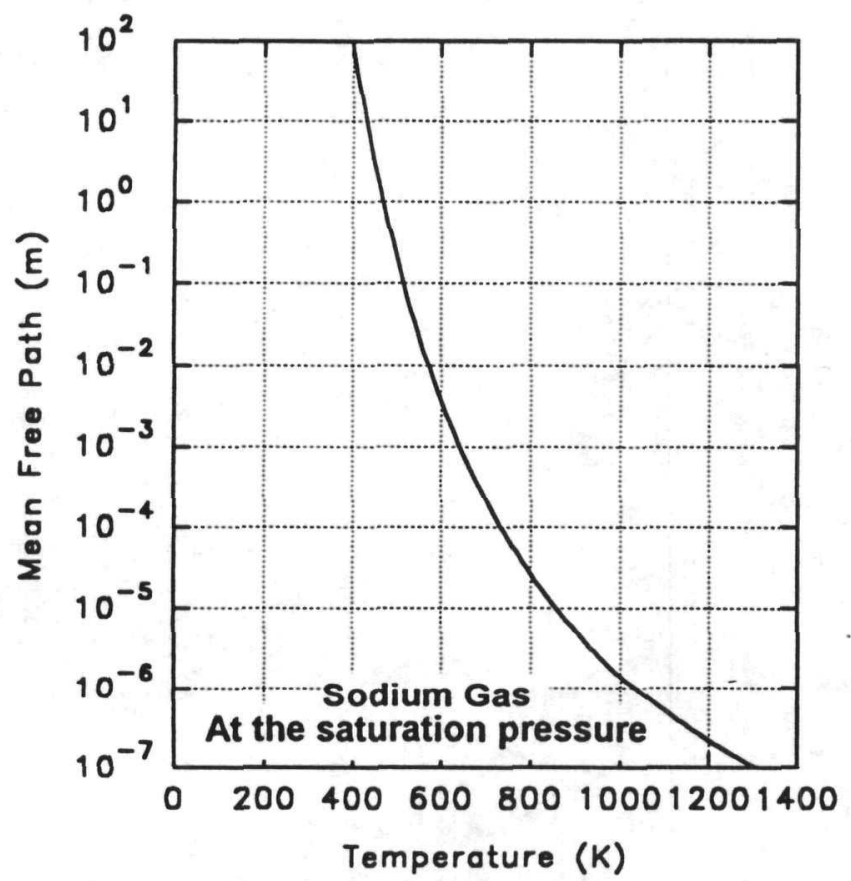

Figure 9. Estimated mean free path for saturated sodium vapor as a function of temperature.

The difference between cooling the gas under long mean free path conditions (the usual assumption) and short mean free path conditions (essentially isobaric) is quite small. Even for the very small temperature difference conditions considered in Figures 2 and $3(\Delta \mathrm{T}=100 \mathrm{~K})$ the efficiency for the long mean free path cycle (a-b-c-d-e-f-g-a) is $7.89 \%$, while the efficiency along the isobaric/short mean free path cycle (a-b-c-d"-e-f-g-a) is $7.85 \%$. The same comparison for the case where $T_{h}=1200 \mathrm{~K}$ and $T_{c}=600 \mathrm{~K}$ is $45.8 \%$ versus $45.6 \%$. Thus, with respect to thermodynamics, it is immaterial whether the sodium mean free path is long or short. This is reflected in a T-s diagram such as Figure 3 where the difference between the points (d) and (d") cannot be resolved.

\section{SUMMARY}

The reversible AMTEC thermodynamic cycle is inherently efficient and relatively insensitive to losses related to either pressurizing and heating the liquid or cooling the low pressure gas to the condensing temperature. The high thermodynamic efficiency is a result of the large entropy (and volume) change associated with the change in state from sodium liquid to sodium gas and the incompressible nature of liquid sodium. The entropy changes associated with heating sodium (liquid or gas) or cooling sodium gas are small compared to the isothermal heat input or rejection steps and entropy changes associated with liquid pressurization (or depressurization) are entirely negligible. Thus, the reversible AMTEC cycle closely approximates a Carnot cycle. Actual AMTEC devices, of course, experience considerable irreversible losses which are the focus of extensive experimental effort, but outside the scope of the current paper.

\section{ACKNOWLEDGMENTS}

The work described in this paper was carried out at the Jet Propulsion Laboratory, California Institute of Technology, under contract with the National Aeronautics and Space Administration.

\section{REFERENCES}

1. J.T. Kummer and N. Weber, U.S. Patent 3,458,356 (1968), Assigned to Ford Motor Company.

2. N. Weber, Energy Conversion, 14, 1-8 (1974).

3. T. Cole, Science, 221(4614), 915-920 (1983).

4. R.M. Williams, M.E. Loveland, B. Jeffries-Nakamura, M.L. Underwood, C.P. Bankston, H. Leduc, and J.T. Kummer, J. Electrochemical Society, 137(6), 1709-1716.

5. R.M. Williams, B. Jeffries-Nakamura, M.L. Underwood, C.P. Bankston, and J.T. Kummer, J. Electrochemical Society, 137(6), 1716-1723.

6. M.L. Underwood, D. O'Connor, R.M. Williams, B. Jeffries-Nakamura, M.A. Ryan, and C.P. Bankston, AIAA Journal of Propulsion and Power, in press.

7. M. Sayer, M.F. Bell, B.A. Judd, S. Sherrit, K. El-Assai, and B. Kindl, J. Applied Physics 67(2), 832-841 (1990).

8. H.J. Bomelburg, C.R.F. Smith, H.N. Royden, V.A. Swanson, A.W. Thiele, and R.J. Tuttle, in Sodium-NaK Engineering Handbook, edited by O.J. Foust, Volume 1, 1-167 (1972).

9. N. Weber, J.R. Rasmussen, G. Harkins, and S.L. Olsen, in Proc. of the 23rd Intersociety Energy Conversion Engineering Conference, Vol. 1., edited by D.Y. Goswami, (American Society of Mechanical Engineers, New York) 215 (1988).

10. M.L. Underwood, R. Williams, M.A. Ryan, B. JeffriesNakamura and D. O'Connor, in Ninth Symposium on Space Nuclear Power Systems, AIP Conference Proceedings 246, Part 3, edited by M. S. El-genk and M.D. Hoover (American Institute of Physics, New York) 1331 (1992). 